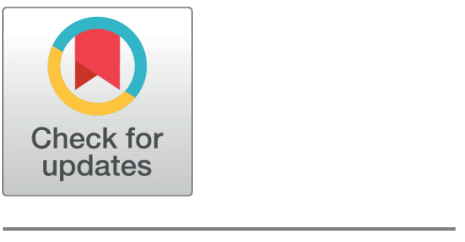

OPEn ACCESS

Received: 12.05 .2021

Accepted: 11.07.2021

Published: 11.08 .2021

Citation: Mishra A (2021) Demystifying the Role of Language in representing students' understanding of Science concepts. Indian Journal of Science and Technology 14(27): 2293-2299. https ://doi.org/10.17485/IJST/v14i27.820

* Corresponding author.

akhileshmishra00@gmail.com

Funding: None

Competing Interests: None

Copyright: (c) 2021 Mishra. This is an open access article distributed under the terms of the Creative Commons Attribution License, which permits unrestricted use, distribution, and reproduction in any medium, provided the original author and source are credited.

Published By Indian Society for Education and Environment (iSee)

ISSN

Print: 0974-6846

Electronic: 0974-5645

\section{Demystifying the Role of Language in representing students' understanding of Science concepts}

\author{
Akhilesh Mishra ${ }^{1 *}$ \\ 1 Senior consultant, National Council of Education Research and Training, Aurobindo Marg, \\ Hauzkhas, Delhi, 110016, India
}

\section{Abstract}

Aims: To explore the role of language in the representation of students' understanding of concepts in the oral as well as the written form through collaborative concept mapping (CCM). The study attempts to identify the nature of difficulties faced by students in the same. Method: A descriptive research design was used for the study. A school was selected purposely of which all the 28 students of a section of class IX were taken as the sample to represent their understanding of selected science concepts through collaborative concept mapping. Students formed 9 groups to draw the concept maps collaboratively. The whole process of CCM by each group was observed to identify the students' actual understanding of the science concepts. The concept maps made by each group were examined qualitatively to compare the representation of students' knowledge in the written form with their actual understanding. Findings: In the study language was found to play an important role in the concrete representation of knowledge in the form of a graphic organizer like a concept map also. Some concepts were identified in the study which were discussed among the group members but not included in the map due to their inability to select appropriate linking words. It was also found that technical terms and labels in science posed a challenge for students. But, in some cases CCmaps provided them a tool through which the correct comprehension of the concepts can be given a concrete form despite having the limited knowledge of language. Novelty: The study provides an insight into the application of CCM as an assessment technique by teachers to compare the students' cognitive structures and their overt representation on paper. It has also identified a specific form of concept map by which students can represent their understanding with the limited knowledge of language.

Keywords: Role of language; Collaborative Concept mapping; understanding of concepts; representation of knowledge; Science

\section{Introduction}

Science as a school subject deals with many complex and abstract concepts at the secondary stage. These are sometimes found difficult to understand by students. 
Teachers are also not able to assess the students' understanding of such concepts as students cannot express them. But, in order to assess and evaluate students' conceptual frameworks of these concepts, teachers have to make students represent their knowledge either in spoken or written forms. A situation may arise when a student is not able to represent his knowledge in either form which leads to his low achievement. One of the reasons for the persistent differential achievement of students in science is language ${ }^{(1)}$. The students with sound knowledge of language can represent their understanding of concepts in a better way. The role of language in the formation and development of concepts is uncontested ${ }^{(2,3)}$. It is equally important in representing these concepts on paper. Hence, it affects the true assessment of the students' knowledge. To overcome these problems teachers should give them the provision of using an alternate method like pictorial representation of their conceptual frameworks. Pictorial representation of concepts is very common in Science. With the help of figures many complex processes or structures are well illustrated and more information can be given in fewer words. So the visual image representation can be an advantage in effectiveness and also in efficiency ${ }^{(4)}$.

Concept maps also give a visual representation to concepts, so; the concepts of science can effectively be represented and communicated by using them ${ }^{(5)}$. Novak described a concept map as "a schematic device for representing a set of concept meanings embedded in a framework of propositions" ${ }^{(6)}$. According to ${ }^{(7)}$ concept maps are mainly made up of the following constituents: concepts, linking words, hierarchy, propositions and cross links. When two or more than two students are engaged to make the concept maps collaboratively, the process is called collaborative concept mapping. Collaborative concept mapping provides a context for students to collaborate their learning by creating a map working with other students ${ }^{(8)}$. Where concept maps can be used by students as a knowledge representation tool, these concept maps as well as the process of their making can be used as an assessment tool by teachers. However, there are various tools of assessment to assess the understanding of students; most of these tools either use oral mode or written mode of assessment. CCM is a technique by which students conceptual frameworks can be elicited and analyzed by using both the modes. As an assessment tool it can help teachers to study the process of meaning making among students as well as to analyze their individual conceptual frameworks in science by giving them a concrete representation in the form of concept maps.

As discussed above, CC Map can be used as a knowledge representation tool by students as it gives a diagrammatic representation of concepts ${ }^{(9)}$ but studies by ${ }^{(10,11)}$ suggest that it also requires language to make the concept map more informative and self-explanatory. According to these studies, appropriate linking words should be chosen to form a meaningful statement. Linking words bring objectivity and precision in the concept map. According to Meena kharatmal, language plays an important role in the selection of appropriate linking words to make a proposition meaningful by connecting two or more concepts ${ }^{(10)}$. Language is more important when students make these maps in a collaborative setting as when students communicate their learning with each other, they are working in two environments; cognitive aspect of learning and linguistic aspect. These are interlinked in the sense that one can act as the stimulus for the other. Individual cognition and collaboration in the knowledge construction process affect each other ${ }^{(12)}$. CCM gives students a platform to externalize internal thoughts, while collaboration is a venue for exploring and discussing such externalizations ${ }^{(13)}$. Language is important in both the situation in discussing the concepts orally and presenting their understanding in the written form. Hence, the present study was conducted using CCM as a knowledge representation tool by students to identify the role of language while representing the understanding of science concepts.

The previous research conducted on concept mapping shows inconsistent findings with respect to the role of language in concept maps. Some studies mentioned concept maps as the visual representation of mental structures of students which indicate that the concept maps give students a medium to represent their cognitive structures as it is on paper ${ }^{(6,7)}$ but according to ${ }^{(10,11)} \mathrm{CM}$ also requires a sound knowledge of language to communicate the accurate knowledge in science. So, the study attempted to answer the research questions: a) Can concept maps facilitate the representation of students' understanding in a concrete manner with the limited knowledge of language? b) If the inappropriate linking words or invalid propositions may act as a barrier in representation of the understanding of the students. c) If CM is used in a collaborative setting then, how the language will mediate the process of knowledge construction. e) Can CCM be used as an assessment technique by teachers to elicit students' actual conceptual frameworks which may be different from their written representation of knowledge?

\subsection{Objectives}

1. To identify the concepts which are comprehended by students through interaction with each other during CCM.

2. To analyze the nature of difficulties faced by the students in representing the concepts in the form of concept maps.

(a) To examine the linking words used to make propositions in the concept maps.

(b) To analyze the propositions made in concept maps to represent the understanding of the focus question.

3. To compare the actual understanding and its representation on paper through concept mapping. 
4. To explore the role of language in the representation of students' understanding of concepts.

\section{Methodology}

It is an exploratory descriptive study which includes exploring the role of language when collaborative concept mapping is used to elicit and analyze the students' understanding in science. For the present study purposive sampling technique was used. A secondary school situated in North West Delhi was selected purposely where a trained graduate teacher of science used to teach and summarize the science concepts using Collaborative concept mapping in her regular classrooms. The students of secondary classes were familiar with the process of concept mapping. The school had 4 sections of class IX. Any one section of class IX of the school was randomly selected. It had 28 students. The students were asked to draw the concept maps collaboratively for the following selected focus questions identified from the topics taught by their teacher recently in the class.

1. Relative density

2. Buoyancy

3. Biodiversity

4. Four kingdoms i.e. Monera, Protista, Fungi and Plant kingdom

5. Invertebrates of animal kingdom

6. Vertebrates of animal kingdom

For the activity, all the 28 students of the class divided themselves into 9 groups. 3 groups consisted of 4 students, 4 groups of 3 students and 2 groups of 2 students were made as explained in Table 1.

Table 1. Groups formed for the study

\begin{tabular}{llll}
\hline S. No. & No. of students in a group & No. of groups & Total students \\
\hline 1. & 4 & 3 & 12 \\
2. & 3 & 4 & 12 \\
3. & 2 & 2 & 04 \\
\hline & Total & 9 & 28 \\
\hline
\end{tabular}

Students were free to choose their partners so they made their groups with the students of their choice from the class for the collaborative concept mapping activity.

\subsection{Tools and techniques}

1. Observation: Observation is an important tool to comprehend the students' understanding in the selected topics of science and their collaboration during the activity. In the present study, observation has been used as a technique to observe the students discourse during construction of concept maps. It was a non-participating observation in which the whole process of concept mapping by each group of students was recorded with the help of a video camera so that it could be analyzed later. The observation was done without bringing it into the notice of students to ensure their natural behavior. The focus of the observation was the dynamics of students' interaction and the kind of oral discourse generated during the process of their meaning making. The whole process of concept mapping by each group of students was observed for identifying the actual understanding of the science concepts by the students.

2. Content analysis: The content of the concept maps presented by each group were examined for the type of concepts and linking words used by the groups to make propositions which represent their knowledge of the given topic of science.

\section{Result and discussion}

In the study language was found to play an important role in the concrete representation of knowledge in the form of a graphic organizer like a concept map. The discourse generated at the time of concept mapping helped to identify the actual understanding of the concepts. There were some concepts discussed among the group members but not included in the map. The major reason for not including such concepts was found to be inability to select appropriate linking words. There were some concept maps where precise propositions could not be formed due to the lack of appropriate linking words. The finding of the study is supported by ${ }^{(11)}$ acco $r$ rding to which "Though we may think that there can be innumerable number of linking words, if 
we look closely into any expert domain in any science, we realize that the number of kinds of linking words is limited." Therefore students found it difficult to select appropriate linking words.

Studies suggest that a concept map can be wrong, if propositions are incorrect as, it gives rise to ambiguity in concept maps. That's why experts tend to use more well-defined linking words ${ }^{(11,14)}$. Similar results were found in the study as there were many propositions in the concept maps made by the students which were grammatically incorrect because of the incorrect linking words. These propositions could not communicate the true knowledge of students. From the discussion among group members it seemed that they had an understanding of the below mentioned concepts but could not represent it in the form of concept map due to their limited knowledge of language. The propositions shown in Table 2 are the examples reflecting children's inability to meaningfully put forth their understanding.

Table 2. Comparison between students' actual understanding and its representation in concept maps

\begin{tabular}{|c|c|c|}
\hline $\begin{array}{l}\text { S. } \\
\text { No }\end{array}$ & Propositions written in concept map & $\begin{array}{l}\text { Students wanted to express (inferred from the discourse during CCM } \\
\text { activity) }\end{array}$ \\
\hline 1. & Force consists of pressure and thrust. & Force can be applied as pressure and thrust. \\
\hline 2. & Gravitation includes thrust and pressure. & Gravitation affects thrust and pressure. \\
\hline 3. & Buoyant force formula of weight of water. & Buoyant force is equal to the weight of the liquid displaced. \\
\hline 4. & Buoyancy consists of sinking and floating. & Buoyancy affects sinking and floating. \\
\hline 5. & Pascal effects of pressure buoyancy and fluid & The effect of pressure in fluid is known as buoyancy and measured in Pascal. \\
\hline 6 & Pressure influences buoyant force. & Pressure on object is due to buoyant force. \\
\hline 7 & Pressure is perpendicular to force per unit area. & Pressure is equal to force per unit area. \\
\hline 8 & Archimedes principle is based on buoyant force. & Archimedes principle helps to calculate buoyant force. \\
\hline 9 & Biodiversity contains taxonomy and nomenclature. & Taxonomy and nomenclature help to study Biodiversity. \\
\hline 10 & Biodiversity consist of basis of classification. & Basis of classification is required to study Biodiversity. \\
\hline 11 & Basis of classification includes taxonomy. & Taxonomy deals with classifying the organism and basis of classification. \\
\hline 12 & Mammals means humans. & Mammals include humans. \\
\hline
\end{tabular}

It was reflected from the CCM activity that students faced difficulty in finding appropriate linking words to make valid propositions. The finding was supported by the study conducted by Leblebicioglu ${ }^{(15)}$ in which the participants accepted that it was easier to state relationships verbally, but it is difficult to place them on a concept map. While in the present study, some instances were identified where a group left a proposition only because it could not find any suitable linking word to form a meaningful proposition e.g. Group 9 wanted to write the characteristics of pisces that they are aquatic, and they lay eggs but due to their inability to come up with an appropriate linking word they decided not to include these statements in the map. In such cases insufficient knowledge of scientific language acted as a barrier in expression of children's thoughts in written form. The finding is in sync with the findings of ${ }^{(10,11,15)}$ which acknowledged that students begin with a rich tapestry of folk language but, when they begin to learn science; they are required to weed out expressions.

The words that comprise the science classroom language fall into two broad components: the technical and non-technical. The former comprises technical words which are specific to a science subject or discipline: photosynthesis, respiration and genes in biology; momentum, capacitance and voltage in physics; atoms, elements and cations in chemistry ${ }^{(16)}$. It was also identified from the conversation of the students during the concept mapping that technical terms and labels in science posed a challenge for students. The same issue was identified in a study of science teaching and learning in Fijis primary and secondary schools where students faced the problems in coping with scientific terminology, and in expressing ideas in their own words ${ }^{(17)}$. Therefore, it was identified from the study that knowledge of scientific terms also plays an important part in expressing the learners' understanding of science concepts even through concept maps.

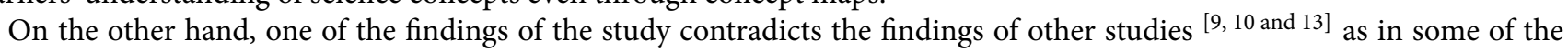
focus questions, students were able to communicate their ideas or thoughts through their concept map in spite of forming inappropriate propositions. Here, insufficient knowledge of language could not be called a barrier. In the focus questions 4,5 and 6 most of the groups made a spoke type concept map. Syntax of language did not play as important a role in these concept maps as in chain and network type concept maps as shown in Figure 1. 


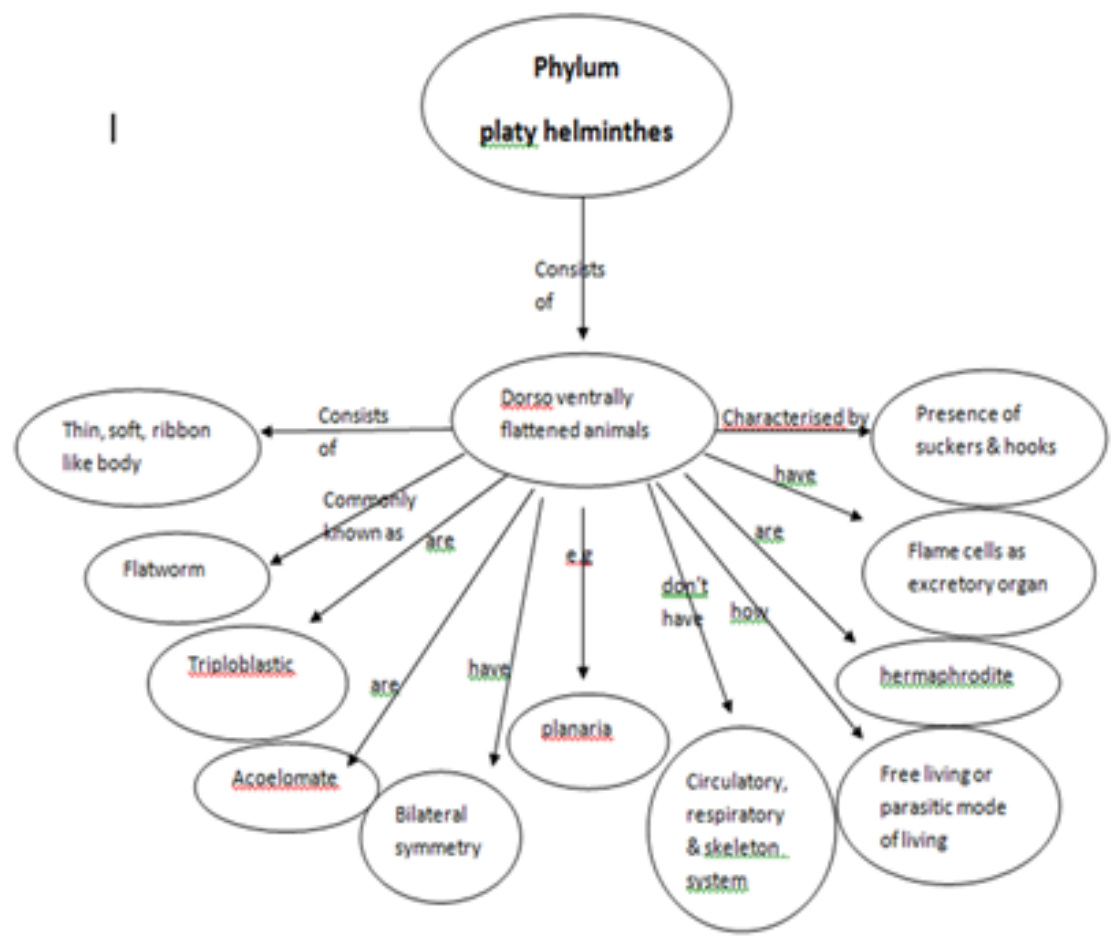

Fig 1. A model of spoke type concept map showing the characteristics of Phylum Platy helminthes

In the present study also it was noted that in the focus question 4 the group 3 connected all the four kingdoms in spoke type by a linking word "are" illustrated in Figure 2.

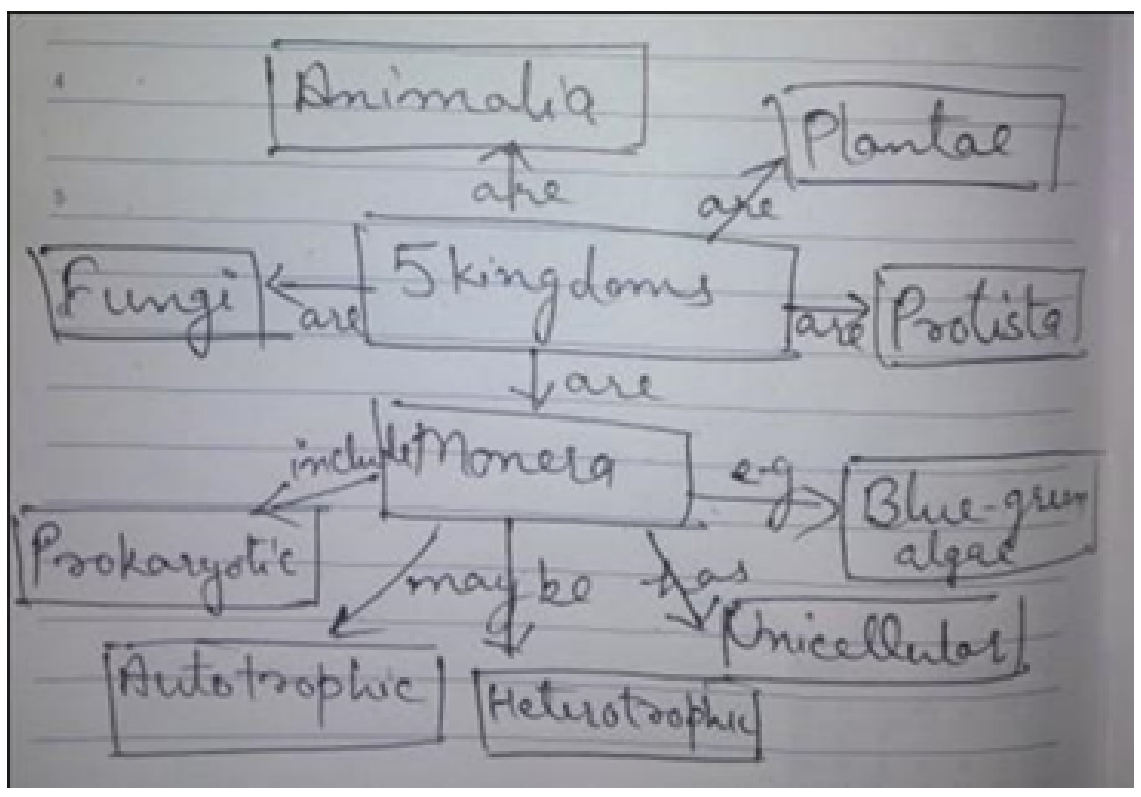

Fig 2. Spoke type concept map made by group 3 on focus question 4

Characteristics of Kingdom Monera were also written in spoke manner. Though the linking words used in the concept maps of these focus questions were limited i.e. "are, includes, example, characteristics". But no proposition could be called incorrect. All propositions including the concepts and linking words were complete in themselves so even in the lack of suitable linking 
words the concept map was able to communicate students' understanding. Though, spoke type of concept maps indicate novice (superficial) understanding of concepts by students ${ }^{(18)}$. But, in this type of concept maps language did not emerge as a barrier in representing a group's knowledge on paper as it requires a chain of propositions radiating from a central concept including no or very less cross links. Technically that map may not be appropriate but all propositions were meaningful and easily understood by the evaluator. Therefore, it was concluded from the study that students can represent their understanding on paper with the limited knowledge of language by selecting the spoke type of concept map.

The study has demystified a vital role of language in representing science knowledge through collaborative concept maps. The major finding of the study is that representation of science concepts in the form of concept maps also requires accurate use of language as inappropriate linking words lead to invalid statements (table 2). Moreover, the structure of the concept map determines the extent of the usage of language in it. The importance of syntax of the language decreases from network to chain type and least in spoke type. It was also identified in the study that by using spoke type concept maps students were able to communicate their conceptual frameworks despite their limited knowledge of language. Hence, spoke type concept maps give students a way out to overcome the barrier of language in representing their understanding in a concrete manner.

\section{Conclusion}

In the present study, collaborative concept mapping (CCM) provided a context in which both the modes of language; i.e. written and spoken, were used by students. Therefore, it emerged as a strong tool which can be used by students to represent their knowledge and by teachers as an effective assessment tool to assess the students' understanding about the concepts. The study gives an insight that teachers can use it as a diagnostic tool also as the discourse generated at the time of CCM activity reveals the process of knowledge construction in students explicitly which can be used to identify the points of difficulty in understanding the concepts. Language was found to play an important role in communicating and representing knowledge in the net and chain types of concept map. In these forms, inappropriate linking words lead to invalid propositions. Therefore, students should be trained to develop language competency if teachers are to use these forms of concept maps to represent students' cognitive structures. The study identified that the syntax of language did not play a vital role in spoke type concept maps. Therefore, students can use spoke form of concept maps to represent their knowledge in case of their limited knowledge of language. The point is to be mentioned that the present study is limited to certain selected topics of science in which spoke type concept maps may be able to communicate the students' knowledge but it may not be possible to make spoke type concept maps in every given topic. The study gave an insight that students may not represent their whole knowledge on paper due to certain constraints. One of such constraints, identified in the study, is limited knowledge of language. So, it is suggested that some more ways except CCM should be found to give the students an opportunity to represent their actual understanding in concrete form. The study is limited to exploring the role of language in representation of students' science knowledge through CCM. Some further research can be taken up to identify the role of other factors like the focus question of concept map, size of the group, learning style of the group members, achievement level of group members etc. which can affect the discourse during the activity.

\section{References}

1) Msimanga A, Denley P, Gumede N. The Pedagogical Role of Language in Science Teaching and Learning in South Africa: A Review of Research 19902015. African Journal of Research in Mathematics, Science and Technology Education. 2017;21(3):245-255. Available from: https://dx.doi.org/10.1080/ 18117295.2017.1367874.

2) Oyoo SO. Language in Science Classrooms: An Analysis of Physics Teachers' Use of and Beliefs About Language. Research in Science Education. 2012;42(5):849-873. Available from: https://dx.doi.org/10.1007/s11165-011-9228-3.

3) Khurana P, Sharma S. Role of language in teaching-learning science: Experiences of pre-service student teachers. Scholarly Research Journal for Humanity, Science and English Language. 2017;4(19):4396-4404. Available from: http://www.srjis.com/pages/pdfFiles/148877472026.\%20PRIYA\%20KHURANA. pdf.

4) Müller H, Foncubierta A, Lin C, Eggel I. Determining the importance of figures in journal articles to find representative images. Progress in Biomedical Optics and Imaging - Proceedings of SPIE. 2013;(8674). Available from: 10.1117/12.2007843.

5) Sivaraman SK. Concept mapping, an innovative educational tool in learning biochemistry. International Journal of Medical Science and Education. 2020;7(3):1-5.

6) Novak JD, Gowin DB. Learning how to learn. New York. Cambridge University Press. 1984. Available from: https://doi.org/10.1017/CBO9781139173469.

7) Novak JD, Cañas AJ. The Theory Underlying Concept Maps and How to Construct and Use Them, Technical Report IHMC Cmap Tools . . Available from: http://cmap.ihmc.us/publications/researchpapers/TheoryUnderlyingConceptMaps.pdf.

8) Daley BJ, Durning SJ, Torre DM. Using Concept Maps to Create Meaningful Learning in Medical Education;vol. 5. Association for Medical Education in Europe (AMEE). 2016. Available from: https://dx.doi.org/10.15694/mep.2016.000019.

9) Ivanov A, Cyr D. The Concept Plot: A Concept Mapping Visualization Tool for Asynchronous Web-Based Brainstorming Sessions. Information Visualization. 2006;5:185-191. Available from: https://dx.doi.org/10.1057/palgrave.ivs.9500130.

10) Kharatmal M, Nagarjuna G. A Proposal to refine concept mapping for effective science learning. In: Cañas AJ, Novak JD, editors. Concept Maps: Theory, Methodology, Technology Proc. of the Second Int. Conference on Concept Mapping. 2006. 
11) Kharatmal M, Nagarjuna G. Using Semantic Reference Set of Linking Words for Concept Mapping in Biology. In: A C, P R, J N, editors. Innovating with Concept Mapping. CMC 2016;vol. 635. Springer. .

12) Engerer VP. Temporality revisited: Dynamicity issues in collaborative digital writing research. Education and Information Technologies. 2021;26:339-370. Available from: https://dx.doi.org/10.1007/s10639-020-10262-9.

13) Webb NM. Peer interaction and learning in small groups. International Journal of Educational Research. 1989;13:21-39. Available from: 10.1016/08830355(89)90014-11118.

14) Tuan LT, Thuan LTB. The Linkages between Concept Maps and Language Learning. Studies in Literature and Language. 2011;2(1):128-146.

15) Leblebicioglu G. Concept maps and language: A Turkish experience. International Journal of Science Education. 2003;25(11):1299-1311. Available from: $10.1080 / 095006903200007027$.

16) Oyoo SO. Helping Learners Become Fluent in the Language of Science Classrooms. 2015. Available from: http://theconversation.com/helping-learnersbecome-fluent-inthe-language- of-science-classrooms-41540.

17) Muralidhar S. The role of language in science education: Some reflections from Fiji. Research in Science Education. 1991;21(1):253-262. Available from: https://dx.doi.org/10.1007/bf02360479.

18) Kinchin IM, Möllits A, Reiska P. Uncovering Types of Knowledge in Concept Maps. Education Sciences. 2019;9(2):131-131. Available from: https: //dx.doi.org/10.3390/educsci9020131. 